\title{
An investigation for integration of deep learning and digital twins towards Construction 4.0
}

\author{
Mergen Kor and Ibrahim Yitmen \\ Department of Construction Engineering and Lighting Science, Jönköping University, \\ Jönköping, Sweden, and \\ Sepehr Alizadehsalehi \\ Project Management Program, Department of Civil and Environmental Engineering, \\ Project Management Program, Department of Civil and Environmenta
Northwestern University, Evanston, Illinois, USA
}

\begin{abstract}
Purpose - The purpose of this paper is to investigate the potential integration of deep learning (DL) and digital twins (DT), referred to as (DDT), to facilitate Construction 4.0 through an exploratory analysis.

Design/methodology/approach - A mixed approach involving qualitative and quantitative analysis was applied to collect data from global industry experts via interviews, focus groups and a questionnaire survey, with an emphasis on the practicality and interoperability of DDT with decision-support capabilities for process optimization.

Findings - Based on the analysis of results, a conceptual model of the framework has been developed. The research findings validate that DL integrated DT model facilitating Construction 4.0 will incorporate cognitive abilities to detect complex and unpredictable actions and reasoning about dynamic process optimization strategies to support decision-making.

Practical implications - The DL integrated DT model will establish an interoperable functionality and develop typologies of models described for autonomous real-time interpretation and decision-making support of complex building systems development based on cognitive capabilities of DT.

Originality/value - The research explores how the technologies work collaboratively to integrate data from different environments in real-time through the interplay of the optimization and simulation during planning and construction. The framework model is a step for the next level of DT involving process automation and control towards Construction 4.0 to be implemented for different phases of the project lifecycle (designplanning-construction).
\end{abstract}

Keywords Digital twins, Deep learning, Artificial intelligence, Internet of things, Simulation, Optimization, Construction 4.0

Paper type Research paper

\section{Introduction}

The architecture, engineering and construction (AEC) sector is notorious for its resource planning, risk management and logistic issues, which frequently lead to design flaws, project delays, cost overruns and contractual conflicts. Building information modeling (BIM) has been used to increase the efficiency of the construction process, eliminate waste during construction and enhance the quality of AEC projects throughout the last several decades. BIM enables the

(C) Mergen Kor, Ibrahim Yitmen and Sepehr Alizadehsalehi. Published by Emerald Publishing Limited. This article is published under the Creative Commons Attribution (CC BY 4.0) licence. Anyone may reproduce, distribute, translate and create derivative works of this article (for both commercial and noncommercial purposes), subject to full attribution to the original publication and authors. The full terms of this licence may be seen at http://creativecommons.org/licences/by/4.0/legalcode

It is the authors' pleasure to express gratitude to all participants, including all design managers, design coordinators, project managers, construction managers, digitalization specialists, BIM manager, BIM coordinator, product manager and platform developer for their contributions to and participation in this research.

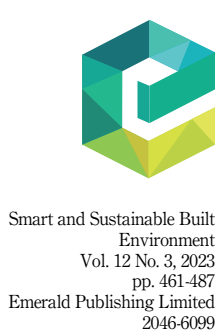

DOI 10.1108/SASBE-08-2021-0148
Received 26 August 2021 Revised 15 November 2021 20 December 2021 Accepted 20 December 2021 
SASBE 12,3

462 early identification and correction of possible issues before they reach the construction site. BIM is beneficial but insufficient, and the AEC sector needs something more substantial (Bakhshi et al., 2022; Rahimian et al., 2021). The existing constraints have prompted research into the use of powerful machine learning (ML) techniques, such as deep learning (DL), to diagnose and predict causes and preventive measures. Over the last few years, the AEC industry has demonstrated an unprecedented level of resiliency. Because of their willingness to take advantage of and adapt to new technologies, enterprises who embrace the latest technology, particularly during the pandemic phase, will place themselves ahead of the competition (Cardno, 2020; Wang et al., 2021). Companies have been encouraged in recent years to adapt to new technologies, techniques, procedures and ways of working to maintain or improve the performance of their projects. As a result of the present epidemic forcing AEC businesses to plan, design, monitor and manage their projects remotely, the transition to digital transformation has been more rapid than most had anticipated (Alizadehsalehi et al., 2020).

Industry 4.0 is a concept that refers to the current trend of technology automation and data exchange, which includes cyber-physical systems (CPSs), the Internet of things (IoT), cloud computing, cognitive computing and developing smart businesses in the AEC industry (Sawhney et al., 2020). In this environment, construction engineering and management are constantly evolving toward digitalization and more intelligent systems to achieve significant automation, productivity and dependability (Pan and Zhang, 2021b; Rahimian et al., 2019). CPSs are defined as systems that work by using various sensors to understand physical components, automatically transferring captured data to cyber components, analyzing the data, and then converting the data into required information via cyber processes that can be used to make required decisions and actions. Intelligent building systems are one of the examples of CPSs. The physical resources in such a system are components and elements of the building and air conditions, and data are received through sensors of these resources, which make up the cyber part of the system. Data used to monitor and control physical resources are frequently transmitted across a communication channel. On the cyber side, calculations are performed to optimal resource use, and a suitable decision is made, based on which physical resources are further managed. CPS, which consists of networked and integrated smart technology, can revolutionize the AEC industry and aid in the development of Construction 4.0. Construction projects that are planned, managed, developed and connected to other autonomous systems are expected to benefit greatly from CPS applications (Yitmen and Alizadehsalehi, 2021a). Currently, design, construction and operation processes are increasingly affected by technologies including value-added monitoring of sensor network data, data management in secure and resilient storage systems based on semantic models, and engineering system simulation and optimization (Boje et al., 2020).

CPS describes how multiple physical systems might work together to incorporate sensors, communication, processing and control in a large-scale cyberinfrastructure. Digital twin (DT) construction, on the other hand, is a new engineering model for controlling construction production that uses data streaming and unique capabilities from multiple site-monitoring systems (Sacks et al., 2020). In the AEC sector, a DT performs artificially intelligent tasks such as providing correct status information, proactively analyzing and optimizing ongoing design and planning, and developing new services to maximize its value. Researchers in the AEC industry have made tremendous advances and significant progress in order to keep pace with the rate at which DL is being applied (Galanos and Chronis, 2021; Hou et al., 2021a; Ma et al., 2020; Zhong et al., 2020b). The adoption of DLs in the AEC industry has been aided by the rapid growth of graphics processing unit (GPU)-accelerated computation techniques and structured and labeled data availability (Akinosho et al., 2020).

With current enabling technologies and cutting-edge applications and implementations of DT in the AEC industry, there are still various significant knowledge gaps that must be addressed through continuing study to make DT more capable, dependable and practical in 
real-world applications (Alizadehsalehi and Yitmen, 2021; Yitmen and Alizadehsalehi, 2021b). The cost of having technologies, software and hardware, as well as acquiring and training expert workers, are some of these problems. Others include a lack of completely automated systems, codes, computation, storage, network bandwidth, and a lack of regulations, policies, security and procedures (Alizadehsalehi and Yitmen, 2021). Despite mature IoT techniques, data loss during the transfer process ("Process" might imply as (1) the data are not received by the target recipient, (2) the data are not being sent from the sender or

(3) the data are being received but the recipient's processor trims the data, and the recipient chooses not to store all the received data) is still a problem due to various reasons such as software incompatibility and data fading (the gradual degradation of the bits on storage media that are not in constant use). The current simulation methodologies for the built environment are generally not correlated with the real-time environmental data (ur Rehman et al., 2019; Wang et al., 2020). Not only does the next generation of DT allows real-time visualization and prediction to aid decision-making, but it also provides autonomous feedback and management of the built environment (Deng et al., 2021).

Following up on previous research, there is still a lack of knowledge about the true potential impact of DT integration, DL and IoT, which are all connected to self-learning hybrid models with proactive cognitive capabilities for smart planning, design and construction. In this research, the goal is to investigate the potential integration of DT and DL (DDT) to facilitate smart planning and construction by performing an explorative analysis in order to discover and close this gap. In alignment with the study's purpose, mainly three research questions are posed:

$R Q 1$. What constitutes technically justifiable (components, characteristics and requirements) for a digital platform integrating DT and DL to facilitate smart planning and construction?

$R Q 2$. How can capacity be developed in order to seize opportunities and overcome constraints on implementing DL integrated DT applications to simulate and optimize planning and construction processes autonomously and collaboratively?

RQ3. How can this DDT become successful in addressing the potential values to be created for construction companies, engineering consulting firms, facility operators, real estate agents and owners (clients) when utilizing such a DT model?

The main contribution to the knowledge domain is an insight into the DL integrated DT model that will establish an interoperable functionality and develop typologies of models described for autonomous real-time interpretation and decision-making support for complex building systems development, based on the cognitive capabilities of DT. Section 2 of this article begins with a review of prior work on the concepts of Construction 4.0, DT, $\mathrm{DL}$ and IoT in the AEC industry, as illustrated in Figure 1. The applied research method, which includes a hybrid approach of quantitative and qualitative assessments, is discussed in Section three. The observations and analysis of the data are presented in Section 4. Decision support capabilities, integrability enablement and practical consequences are discussed in Section 5. Finally, this article presents conclusions, recommendations and future directions for DT/DL integration in various construction management sectors in Section six.

\section{Literature review}

This section outlines the key-related works in five main areas relevant to this paper: (1) Construction 4.0; (2) DT in AEC industry; (3) DL; (4) IoT and (5) process optimization. 


\section{SASBE 12,3}

Figure 1.

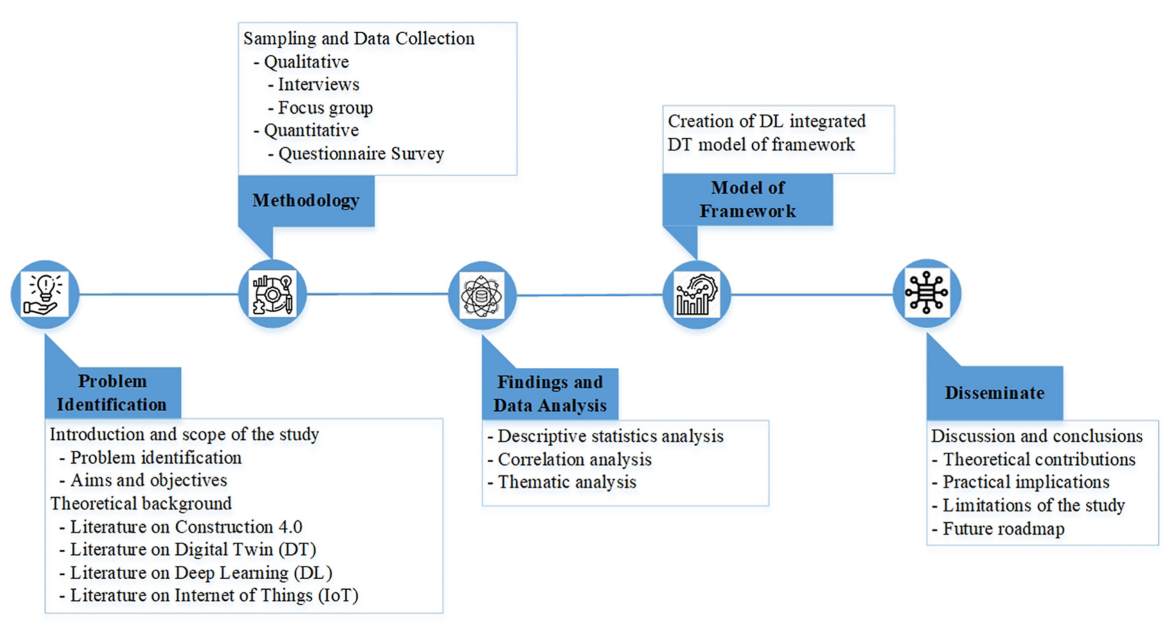

\subsection{Construction 4.0}

Construction 4.0 is the construction industry's equivalent of Industry 4.0 , and it is the process of deploying CPSs to encourage the digitization of the construction industry to achieve maximum performance. To promote maximum project performance, Construction 4.0 incorporates technology that supports smart construction sites, simulation and virtualization. Prefabrication, 3D printing, automation, extended reality (XR), unmanned aerial vehicles (UAVs), various types of sensors, robots and big data utilized to improve realtime decision-making processes are just a few examples. Construction 4.0 is primarily divided into three scenarios:

Physical domain/automation, which refers to digital end-to-end engineering integration and technologies for the automation of the physical construction environment.

(1) Simulations and modeling, which refers to modeling and simulation tools for the design, construction and operation of buildings and infrastructures

(2) Digitalization, which refers to digital end-to-end engineering integration and technologies for the automation of the physical construction environment.

Construction 4.0 will allow firms to increase productivity, reduce project delays and costs, manage complexity, and improve safety, quality and resource economy (Craveiroa et al., 2019).

AEC projects are increasingly becoming more attractive, energy-efficient, comfortable, affordable, safe and sustainable as innovative technology and materials are developed. Construction has reached a new era, recent advancements in materials and cutting-edge technologies (such as AI, robotics, nanotechnology, 3D printing and biotech) (Qi et al., 2018). The opportunities afforded by big data and the IoT, as well as technological advancements driving down the cost of sensors, data storage and computer services are causing massive shifts.

Advanced technology, tools and materials for the digital transformation of the construction industry provides a comprehensive overview of developments in materials, emerging trends, cutting-edge technologies, and strategies in the fields of smart building design, construction and operation, providing the reader with a comprehensive guideline on how to take advantage of the new opportunities provided by the digital transformation. All of these factors, as indicated in Figure 2, contribute to the development of Construction 4.0. 


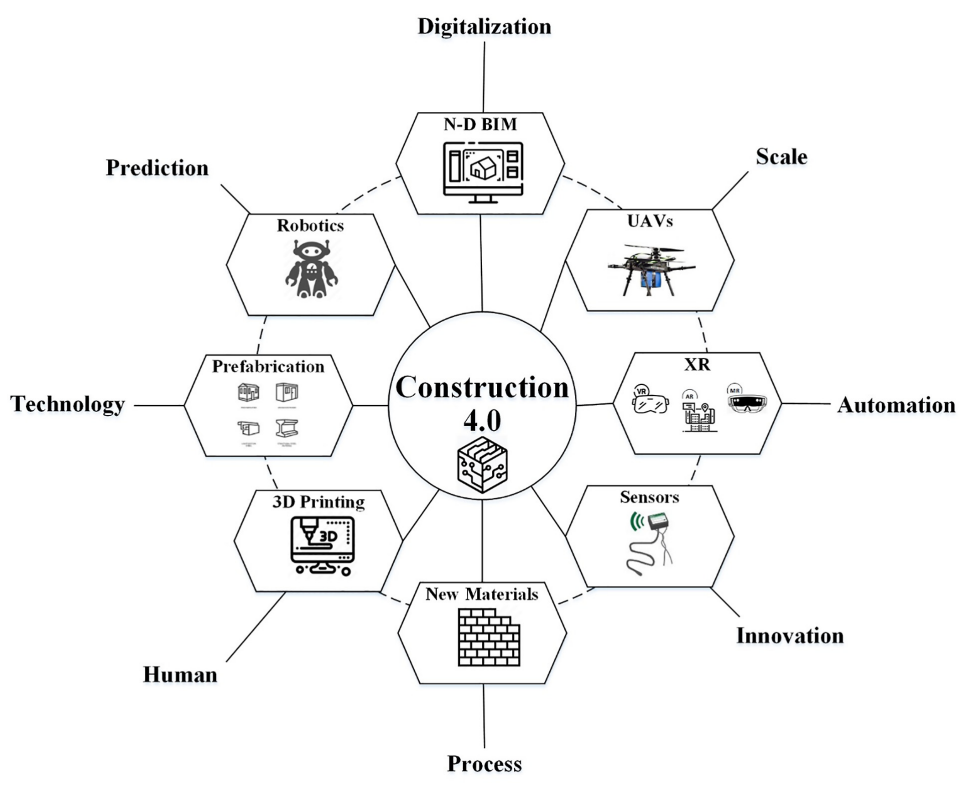

\subsection{Digital twin (DT)}

The CPS for visualization, modeling, simulation, analysis, prediction and optimization is realized in DT (Tao et al., 2019; Yitmen et al., 2021). A practical loop comprises three primary components: a physical entity, a virtual entity and a data link. In the DT, there are commonly two approaches for dynamic mapping. Inspection data are collected in the actual world and then transferred to the simulated environment for further assessment (Aheleroff et al., 2021; Dawood et al., 2020; Pan and Zhang, 2021a; Qi et al., 2018). The virtual model runs simulations to obtain optimum predictions, allowing it to provide quick solutions that adapt natural processes to changing conditions (Pan and Zhang, 2021b). DT combines real-time and historical data from physics-based models, physical systems and advanced analytics to produce digital equivalents with high integrity, awareness and adaptability, allowing planning and construction entities to receive predictive services. It facilitates real-time monitoring, simulation, optimization and control of CPSs. In order to provide on-demand prediction services to users in the physical and virtual worlds, DT-based CPS must continuously acquire, integrate, analyze, simulate and synchronize data. Ubiquitous connection and smart objects, enhanced analytics, cooperative decision-making, autonomous and rapid model construction and updates, and autonomous disturbance handling and resilience control are the major characteristics and requirements for DT integration in CPS (Lee et al., 2020). Deng et al. (2021) created a five-level ladder taxonomy to capture the transition from BIM to DT. BIM Level 1, BIM Level 2, supported simulations, BIM Level 3 integrated with IoT, BIM Level 4 integrated with AI approaches for forecasts and level 5-optimal DT are the levels. Each level of the ladder taxonomy was separated into several sub-categories focused on separate research fields assigned to the design, construction, operation and demolition phases based on the building life cycle (Yitmen et al., 2021). As a result, BIM Level 4+AI exemplifies the use of BIM and AI techniques to improve decision-making and database predictions, while level 5 ideal DTs exemplifies interaction and optimization (Deng et al., 2021). 
SASBE 12,3

To discover discrepancies to create and describe "Digital twin construction (CDT)," Boje et al. (2020) analyzed BIM literature on construction applications and examined DT uses in adjacent fields. They proposed that a CDT can be developed over three generations. The first generation is represented as an up-to-date version of BIM on construction sites; the second generation includes semantics, defining CDTs as "enhanced restricted intelligence monitoring platforms where a common web-language system is deployed to represent the DT with all its integrated IoT devices, thus forming a knowledge base"; and the third generation, "To build a self-reliant, self-updatable, and self-learning DT, ML, DL, data mining and analysis capabilities are required." Rausch et al. (2020) show how computational methods may aid in the production of DTs, and how these workflows can be utilized to find optimum and heuristic solutions to difficult situations. Table 1 shows a variety of DT applications based on the most recent research.

\subsection{Deep learning (DL)}

$\mathrm{DL}$ is a subset of ML, which is a subset of artificial intelligence (AI) that uses neural networks to learn unsupervised from unstructured or unlabeled data. AI is a technique that allows a machine to replicate human behavior (Liu et al., 2021; Wu et al., 2019). ML is a method of achieving AI through data-driven algorithms with a key role in making construction "smart" (Feng and Chen, 2021; Xu et al., 2021). Finally, DL is a sort of ML that is inspired by the structure of the human brain, and this structure is referred to as an artificial neural network in DL (Xiao and Kang, 2021). DL algorithms can be used to teach systems how to think like a human brain (Yitmen and Alizadehsalehi, 2021a). DL is part of a larger family of ML approaches that can take raw data and automatically generate the representations needed for tasks like classification, regression, clustering and pattern recognition. In high-dimensional data, DL is extremely effective in detecting complicated structures. It allows for higher levels of abstraction without the need for time-consuming feature engineering, and it performs well in a wide range of applications. However, with the exception of some image classification and language processing tools, feature engineering is almost always required in ML projects. Even with DL, there are limitations (Lee et al., 2020). DL has a wide range of applications, particularly in the AEC in areas like site planning and management (Abdelkader, 2021). Kung et al. (2021) suggested a model based on convolutional neural networks (CNNs) for automatic identification and localization of critical construction defects using images (efflorescence, spalling, cracking and defacement). The findings of this study indicate that combining DL and UAV may effectively detect a variety of external wall defects and enhance detection efficiency. In another research, Ogunseiju et al. investigated the effectiveness of a variation of deep CNNs for recognizing construction worker activities from images of signals from timeseries data using large datasets for training and testing DL algorithms (Ogunseiju et al., 2021). Even though DL is good at handling this type of data, the level of efficiency feasible with the available unlabeled data remains unknown (Akinosho et al., 2020). Based on the most recent research, Table 2 demonstrates a variety of DL uses.

\subsection{Internet of things (IoT)}

The International Organization for Standardization (ISO 2018) defines IoT as "an infrastructure of interconnected objects, people, systems and information resources, coupled with intelligent services that allow them to handle and react to information from the real and virtual environment." As a result, IoT is a hybrid of physical and virtual states that carries physical elements like sensors, actuators, cloud services, communication and protocols with a variety of designs to provide a framework and explanation for IoT systems. The emergence of IoT has been aided by a remarkable expansion in sensor and contemporary communications in recent years. In the construction and industrial sectors, such as 


\begin{tabular}{|c|c|c|c|c|}
\hline$n$ & References & Year & References & \\
\hline 1 & $\begin{array}{l}\text { Alizadehsalehi and } \\
\text { Yitmen (2021) }\end{array}$ & 2021 & $\begin{array}{l}\text { Develop a generic framework called DRX that can be used for } \\
\text { anything from automated construction progress monitoring to } \\
\text { extended reality. It is based on DT and can be used for anything }\end{array}$ & \\
\hline 2 & Alonso et al. (2019) & 2019 & $\begin{array}{l}\text { SPHERE platform was investigated for its potential to improve the } \\
\text { energy performance of buildings }\end{array}$ & \\
\hline 3 & Alshammari et al. (2021) & 2021 & $\begin{array}{l}\text { The topic of cybersecurity for DTs in the built environment was } \\
\text { presented and investigated }\end{array}$ & 467 \\
\hline 4 & Boje et al. (2020) & 2020 & $\begin{array}{l}\text { Examined the many-faceted applications and limitations of BIM, as } \\
\text { well as the necessity of construction DT in the construction industry }\end{array}$ & \\
\hline 5 & $\begin{array}{l}\text { Bosch-Sijtsema et al. } \\
\text { (2021) }\end{array}$ & 2021 & $\begin{array}{l}\text { The applications of digital technologies in the AEC industry were } \\
\text { discussed }\end{array}$ & \\
\hline 6 & Camposano et al. (2021) & 2021 & $\begin{array}{l}\text { The manner in which AEC/FM practitioners describe DTs of built } \\
\text { assets was investigated }\end{array}$ & \\
\hline 7 & Cureton and Dunn (2021) & 2021 & It conducted research on decentralized cities and evasive futures & \\
\hline 8 & Dawood et al. (2020) & 2020 & $\begin{array}{l}\text { AECO's DT, VR, AR and BIM technologies were reviewed, } \\
\text { developed and implemented }\end{array}$ & \\
\hline 9 & $\begin{array}{l}\text { Del Giudice and Osello } \\
\text { (2021) }\end{array}$ & 2021 & $\begin{array}{l}\text { The development of smart cities was the subject of investigation. } \\
\text { DTs serve as the foundation }\end{array}$ & \\
\hline 10 & Deng et al. (2021) & 2021 & $\begin{array}{l}\text { It conducted research on the progression of BIM to DTs in built } \\
\text { environment applications }\end{array}$ & \\
\hline 11 & Götz et al. (2020) & 2020 & It looked into the asset life cycle management system & \\
\hline 12 & Hasan et al. (2021) & 2021 & $\begin{array}{l}\text { AR and DT were used to investigate the operation of construction } \\
\text { machinery and the tracking of work }\end{array}$ & \\
\hline 13 & Hou et al. (2021b) & 2021 & $\begin{array}{l}\text { The applications and challenges of DTs in the construction industry } \\
\text { were discussed }\end{array}$ & \\
\hline 14 & Ozturk (2021) & 2021 & $\begin{array}{l}\text { There has been a discussion of current patterns, gaps and trends in } \\
\text { DT research in the AECO-FM industry as well as future directions } \\
\text { for stakeholders in this industry }\end{array}$ & \\
\hline 15 & $\begin{array}{l}\text { Kaewunruen and Lian } \\
\text { (2019) }\end{array}$ & 2019 & $\begin{array}{l}\text { DT was evaluated for its ability to provide sustainable lifecycle } \\
\text { management for railway turnout systems }\end{array}$ & \\
\hline 16 & Khajavi et al. (2019) & 2019 & The topic of DT for building life cycle management was discussed & \\
\hline 17 & Lu et al. (2019) & 2019 & $\begin{array}{l}\text { The proposed smart asset management framework is based on } \\
\text { distributed ledger technology }\end{array}$ & \\
\hline 18 & Liu et al. (2020) & 2020 & $\begin{array}{l}\text { The investigation into the building's indoor safety management was } \\
\text { conducted }\end{array}$ & \\
\hline 19 & Mathot et al. (2019) & 2019 & $\begin{array}{l}\text { Packhunt.io, the next generation parametric system, was developed } \\
\text { and discussed in conjunction with BIM, DT and mixed reality (XR) } \\
\text { technologies }\end{array}$ & \\
\hline 20 & Menassa (2021) & 2021 & $\begin{array}{l}\text { It was necessary to conduct a systematic review in order to identify } \\
\text { developments in emerging technologies that would facilitate the } \\
\text { transition from BIM to DTs in built environment applications }\end{array}$ & \\
\hline 21 & Pan and Zhang (2021a) & 2021 & $\begin{array}{l}\text { In order to facilitate advanced project management, we developed a } \\
\text { data-driven design framework based on BIM, IoT and data mining }\end{array}$ & \\
\hline 22 & Quaye (2021) & & $\begin{array}{l}\text { A systematic literature review was conducted in conjunction with } \\
\text { interviews with key industry players }\end{array}$ & \\
\hline 23 & Rausch et al. (2020) & 2020 & $\begin{array}{l}\text { The application of a computational algorithm to assist DTs in the } \\
\text { construction process }\end{array}$ & \\
\hline 24 & Villa and Chiaia (2021) & 2021 & $\begin{array}{l}\text { It demonstrated the current state of the art, as well as challenges and } \\
\text { opportunities }\end{array}$ & $\begin{array}{r}\text { Table } 1 . \\
\text { Diverse applications of }\end{array}$ \\
\hline 25 & Yitmen et al. (2021) & 2021 & $\begin{array}{l}\text { A study was conducted to determine the applicability, } \\
\text { interoperability and integrability of an adapted cognitive digital } \\
\text { twin (CDT) model for use in building lifecycle management (BLM) }\end{array}$ & $\begin{array}{l}\text { DT, based on the latest } \\
\text { research in AEC } \\
\text { industry }\end{array}$ \\
\hline
\end{tabular}




\section{SASBE 12,3}

468

\begin{tabular}{ll}
$n$ & References \\
\hline 1 & $\begin{array}{l}\text { Alawadhi and Yan } \\
(2021)\end{array}$
\end{tabular}

2 Chang et al. (2019)

3 Chen and Demachi (2021)

4 Hou et al. (2021a)

$5 \quad$ Kim and Lee (2020)

6 Marzouk and Zaher (2020)

7 Ma et al. (2020)

8 Perez-Perez et al. (2021)

$9 \quad$ Wu et al. (2020)

10 Xue and Zhang (2021)

Table 2.

Diverse applications of $\mathrm{DL}$, based on the latest research in AEC industry

11 Zhong et al. (2020a)
Year Applications

2021 Presented a concept for a hybrid system that uses BIM and hyperrealistic rendering for DL to synthesize data sets for training a neural network for object recognition in photographs, with the goal of building object recognition in photographs

2019 By applying DL and BIM to indoor positioning, we were able to develop a sound-based method

2021 The combination of DL-based object detection and individual detection using geometric relationships analysis resulted in a novel solution for identifying improper use of personal protective equipment

2021 Identified relevant gaps, challenges and future work on DL-based applications for safety management in the AEC industry

2020 With reference images and a deep-learning model, this paper describes a stochastic approach for identifying and appending interior design style information to a design document

2020 DL was used to present a methodology for exploitation of artificial intelligence in facility management using DL

2020 With DL, a methodology for generating synthetic point clouds from 3D BIM models was demonstrated and discussed

2021 Presented an end-to-end DL method, Scan2BIM-NET, for semantically segmenting the structural, architectural and mechanical components present in point cloud data, as well as experimental results demonstrating the method's effectiveness

2020 DL and NLP techniques were used to develop a method for screening patents related to information and communications technology (ICT) in construction

2021 It was proposed that a part-of-speech (POS) tagger tailored to building codes be developed, which would be empowered by DL and transformative rules

2020 In order to improve the efficiency and effectiveness of retrieving queries pertaining to building regulations, a robust end-to-end methodology was developed that integrates information retrieval with a DL model of natural language processing (NLP) (NLP)

transportation, security, health, smart building and automotive, an increasing number of devices and sensors are being implemented. The IoTs' objective is to make everything smarter and more connected. Therefore, a number of technologies are being utilized to improve management efficiency in both the virtual and physical worlds (Lin and Cheung, 2020). Based on the most recent study, Table 3 depicts a variety of IoT applications.

\subsection{Process optimization}

Optimization is a decision-making process for pursuing and delivering feasible, long-term construction solutions. Optimization may make a process completely follow a set of criteria and restrictions by maximizing the expected impacts. During the period of carrying out construction activities on a complicated site, optimization aids in better resource allocation, crew organization, facility layout determination, and making consistent alterations in a reasonable and timely manner (Akanbi et al., 2020; Matar et al., 2013; Oprach et al., 2019). DT entails simulation, prediction and optimization in a virtual model, which can provide fast solutions to manage a realistic process and make it adapt to a changing environment by learning data from many sources (Pan and Zhang, 2021b). Optimization tools will enable process optimization through real-time data and CDT models in the CDT and analytics for the process simulation phase. The outcome of this optimization is used to make judgments for regulating physical entities (Yitmen et al., 2021). 


\begin{tabular}{|c|c|c|c|c|}
\hline$n$ & References & Year & Applications & nstruc \\
\hline 1 & Alavi et al. (2018) & 2018 & $\begin{array}{l}\text { The current state-of-the-art and future trends in the IoTs are discussed in } \\
\text { detail here }\end{array}$ & \\
\hline 2 & Arthur et al. (2018) & 2018 & $\begin{array}{l}\text { The topic of emulation and simulation of IoT-based devices for BIM was } \\
\text { discussed }\end{array}$ & \\
\hline 3 & $\begin{array}{l}\text { Atazadeh et al. } \\
\text { (2019) }\end{array}$ & 2019 & $\begin{array}{l}\text { The use of a BIM environment to communicate the legal ownership of IoT- } \\
\text { generated data in multi-owned buildings has been successful in several } \\
\text { cases }\end{array}$ & 469 \\
\hline 4 & Ding et al. (2018) & 2018 & The use of BIM and the IoTs to construct smart steel bridges was discussed & \\
\hline 5 & Ghosh et al. (2020) & 2020 & $\begin{array}{l}\text { By utilizing a scientific mapping tool, we were able to identify and rank the } \\
\text { perceived importance level of the principal research areas associated with } \\
\text { the IoTs and the construction industry }\end{array}$ & \\
\hline 6 & $\begin{array}{l}\text { Lin and Cheung } \\
(2020)\end{array}$ & 2020 & $\begin{array}{l}\text { The advantages and challenges of integrating IoT technology and Internet- } \\
\text { enabled physical devices in the construction industry were investigated } \\
\text { and identified }\end{array}$ & \\
\hline 7 & $\begin{array}{l}\text { Linares et al. } \\
(2019)\end{array}$ & 2019 & $\begin{array}{l}\text { The technologies for implementing CPSs in the AEC industry were } \\
\text { evaluated }\end{array}$ & \\
\hline 8 & $\begin{array}{l}\text { Lokshina et al. } \\
\text { (2019) }\end{array}$ & 2019 & $\begin{array}{l}\text { Design of a proposed system that makes use of blockchain technology as a } \\
\text { means to secure and control a framework that incorporates integrated IoT } \\
\text { and BIM technologies is considered. Despite the fact that this paper } \\
\text { examines system design as it is applied in a smart museum, the authors } \\
\text { assume that the design is generic and can be applied to other building types }\end{array}$ & \\
\hline 9 & $\begin{array}{l}\text { Malagnino et al. } \\
\text { (2021) }\end{array}$ & 2021 & BIM and IoT for smart and sustainable environments have been reviewed & \\
\hline 10 & Pasini et al. (2016) & 2016 & The proposed IoTs and BIM fr & \\
\hline 11 & Sarkar et al. (2020) & 2020 & $\begin{array}{l}\text { The development of an integrated cloud-based IoTs platform for asset } \\
\text { management of elevated metro rail projects was completed }\end{array}$ & \\
\hline 12 & $\begin{array}{l}\text { Siountri et al. } \\
(2020)\end{array}$ & 2020 & $\begin{array}{l}\text { Research was conducted on the development of smart buildings through } \\
\text { the use of BIM, IoT and blockchain }\end{array}$ & \\
\hline 13 & Tang et al. (2019) & 2019 & $\begin{array}{l}\text { An in-depth examination of the integration of BIM and IoTs devices in the } \\
\text { AEC industry was presented }\end{array}$ & $\begin{array}{l}\text { Diverse applications of } \\
\text { IoT, based on the latest }\end{array}$ \\
\hline 14 & Zhong et al. (2017) & 2017 & $\begin{array}{l}\text { By incorporating IoTs-enabled tools for prefabricated construction, 3D } \\
\text { BIM has been transformed into } \mathrm{nD} \text { BIM }\end{array}$ & $\begin{array}{r}\text { research in AEC } \\
\text { industry }\end{array}$ \\
\hline
\end{tabular}

\section{Research methodology}

The research methodology for this paper is comprised of five steps: a systematic literature review, a quantitative and qualitative digital survey, descriptive statistics and covariance analyses, a thematic analysis and a model of framework development. The systematic literature review is the first step. To acquire information from worldwide industry experts on the applicability and interoperability of DL integrated DT with decision-support capabilities for process optimization, a mixed approach comprising interviews, focus groups and a questionnaire survey was employed. A conceptual model of the framework has been built based on the results of quantitative and qualitative analyses.

\subsection{Sampling and data collection}

3.1.1 Survey. Professionals from design companies, project management consulting firms, contracting firms and IT companies in North America, South America, Europe, Scandinavia, Asia-Pacific and the Middle East made up the survey population. Large (>250 employees), medium (50-250 employees) and small (50 employees) firms are all represented in the sample. A total of 150 companies were contacted via LinkedIn, with one representative from each being requested to take part in the computerized self-administered questionnaire (CSAQ). The research objectives were explained to the participants, as well as the confidentiality and 
SASBE 12,3

anonymity of their responses. A total of 53 completed surveys were received, giving in a $35 \%$ response rate. The participants were asked to discuss their present role, expertise, experiences and the firm they work for. On a five-point Likert scale of 1 (strongly disagree) to 5 (strongly agree), they have indicated how much they agree with the items representing their organization's opinion on the DDT for promoting smart planning and construction statements (strongly agree). Table 4 shows the proportions of firm roles, experiences, sizes and geographies.

3.1.2 Thematic analysis is a method of analyzing data. The interview replies and focus group meeting data were examined thematically, identifying patterns of themes, using the qualitative data analysis program NVivo using a grounded theory coding approach. From chaotic data to a map of the most relevant themes in the data, an iterative method was used. Table 5 shows the characteristics of interviewees as well as interview details. To describe the content, preliminary codes were assigned to the data. Themes were found in the interviews and focus group talks by searching the codes. Themes were then examined, defined and titled. In interviews, the following themes were identified:

(1) Implementation of BIM Level 2 (BIM-supported simulations and collaboration) has a number of advantages.

(2) Implementation challenges for BIM Level 3 (BIM integrated with IoT).

(3) Through semantic models, IoT and AI agents (data analytics, ML and DL) can be integrated.

(4) DT promises to move forward with Construction 4.0 Al's role in DT realization prediction and optimization.

(5) Challenges in DT's ability to optimize construction processes.

(6) Interoperability between DT and DL at a reasonable level for Construction 4.0 added value of DT and DT for construction process optimization.

A focus group meeting was held digitally at House of DTs, hosted by Christina Savian, founder of DTs Club on ClubHouse (www.houseofdigitaltwins.club), to discuss an achievable level of interoperability between DT and DL in the context of Construction 4.0, as well as the potential added value of integrating DT and DL for construction process optimization. Table 6 illustrates this. Professionals from both the manufacturing and construction industries were among the attendees at the gathering.

3.1.3 Model of framework development. The information collected from the literature research, where use cases were identified, and the responses gathered from the questionnaire, which reported on the dynamics of technological ecosystems and current asset life cycle management practices, served as the foundation for the model development. One of the most essential principles of the model architecture is represented by the integrability enablers. As a consequence, the thematic NVivo ${ }^{\circledR}$ analysis of the open-ended questions section, where industry professionals were asked to freely discuss their current and planned digitization initiatives, including DL, DT and IoT projects, was the primary source of insights. The application cases of the DDT, as well as their functional interoperability with current practice and technological ecosystems, are emphasized in the framework model. It also outlines the degree to which it will be able to achieve its main objective of providing "live" and information-rich management applications and decision support tools.

\section{Findings and analysis of results}

The findings are divided into three sections, and a model of the framework is provided in each section. The survey results are presented in the first two sections, while the third piece 


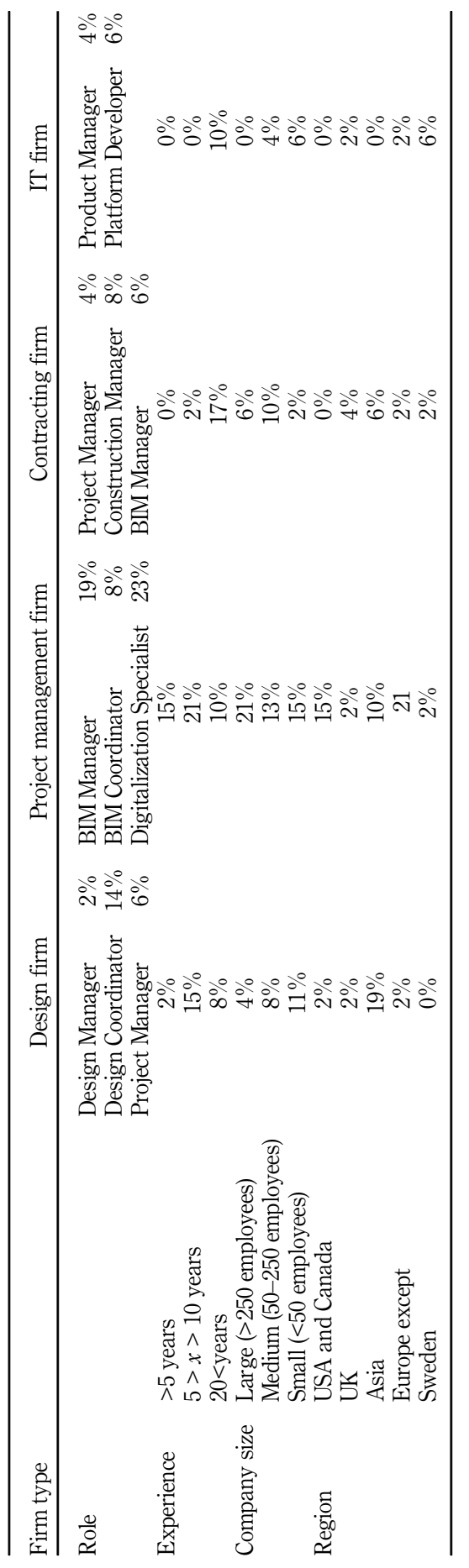

Construction

4.0

471

Table 4. Company region, size and role in percentage 


\begin{tabular}{|c|c|c|c|c|c|c|}
\hline $\begin{array}{l}\text { SASBE } \\
12,3\end{array}$ & $\underline{\mathrm{ID}}$ & Position & Organization & Location & Interview type & $\begin{array}{l}\text { Interview } \\
\text { duration } \\
\end{array}$ \\
\hline \multirow[b]{4}{*}{472} & 1 & BIM specialist & IT firm & California, USA & CSAQ & $20 \min$ \\
\hline & 2 & BIM specialist & $\begin{array}{l}\text { Project management } \\
\text { firm }\end{array}$ & Dubai, UAE & CSAQ & $20 \mathrm{~min}$ \\
\hline & 3 & BIM manager & Design firm & Vancouver, Canada & CSAQ & $20 \mathrm{~min}$ \\
\hline & 4 & BIM manager & $\begin{array}{l}\text { Project management } \\
\text { firm }\end{array}$ & Sydney, Australia & $\begin{array}{l}\text { Online } \\
\text { meeting }\end{array}$ & $55 \mathrm{~min}$ \\
\hline \multirow{8}{*}{$\begin{array}{l}\text { Table } 5 \text {. } \\
\text { Profiles of interviewees } \\
\text { and interview details }\end{array}$} & 5 & BIM specialist & IT firm & Stockholm, Sweden & CSAQ & $25 \mathrm{~min}$ \\
\hline & 6 & Project manager & $\begin{array}{l}\text { Project management } \\
\text { firm }\end{array}$ & Stockholm, Sweden & CSAQ & $20 \mathrm{~min}$ \\
\hline & 7 & Construction manager & Contracting firm & $\begin{array}{l}\text { Gothenburg, } \\
\text { Sweden }\end{array}$ & CSAQ & $30 \mathrm{~min}$ \\
\hline & 8 & $\begin{array}{l}\text { Digitalization } \\
\text { specialist }\end{array}$ & Design firm & $\begin{array}{l}\text { Gothenburg, } \\
\text { Sweden }\end{array}$ & CSAQ & $20 \mathrm{~min}$ \\
\hline & 9 & $\begin{array}{l}\text { Digitalization } \\
\text { specialist }\end{array}$ & Design firm & $\begin{array}{l}\text { Gothenburg, } \\
\text { Sweden }\end{array}$ & CSAQ & $25 \mathrm{~min}$ \\
\hline & 10 & $\begin{array}{l}\text { Digitalization } \\
\text { specialist }\end{array}$ & Design firm & Malmö, Sweden & CSAQ & $20 \mathrm{~min}$ \\
\hline & 11 & BIM manager & Contracting firm & Malmö, Sweden & CSAQ & $25 \min$ \\
\hline & 12 & Construction manager & Contracting firm & $\begin{array}{l}\text { Gothenburg, } \\
\text { Sweden }\end{array}$ & CSAQ & $30 \mathrm{~min}$ \\
\hline
\end{tabular}

Table 6.

Profiles of focus group meeting and participants' details

\begin{tabular}{llllll}
\hline ID & Position & Organization & Location & Interview type & $\begin{array}{l}\text { Interview } \\
\text { duration }\end{array}$ \\
\hline 1 & BIM specialist & IT firm & California, USA & Online meeting & $75 \mathrm{~min}$ \\
2 & BIM specialist & IT firm & SJ, Costa Rica & Online meeting & $75 \mathrm{~min}$ \\
3 & Design manager & Design firm & Sydney, Australia & Online meeting & $75 \mathrm{~min}$ \\
4 & BIM manager & Project management firm & Sydney, Australia & Online meeting & $75 \mathrm{~min}$ \\
5 & BIM manager & IT firm & DC, USA & Online meeting & $75 \mathrm{~min}$ \\
6 & BIM specialist & IT firm & DC, USA & Online meeting & $75 \mathrm{~min}$ \\
\hline
\end{tabular}

concentrates on the results of interviews and focus group meetings. The framework for a DL integrated DT model is discussed in the fourth part.

\subsection{Descriptive statistics}

Table 7 presents descriptive statistics for questionnaire responses, including mean values and standard deviations. The questionnaire responses were divided into two groups. As an overview of the perception of the concepts by industry professionals, the summarized statistics reveal some noteworthy understandings. It was discovered that the mean scores for 22 out of a total of 32 questions were higher than 4.00 out of a possible 5.00. The overall mean rating for the proposed model was 4.064, indicating that industry professionals support approaching DL integrated DT development for process optimization and decision-making purposes, and that integrability enablers confirm the progression towards Construction 4.0 as a result.

It was discovered that "DT can support visualizations, simulations and scenario generation applications" from DT has a mean value of 4.13. According to the relative 


Factors/References
Construction 4.0 (Hong et al., 2021; Kumar,
2018; Li et al., 2020; Wu, 2018)
2018; Li et al., 2020; Wu, 2018)

Digital twin (Alizadehsalehi and Yitmen, 2021; Deng et al., 2021; Meža et al., 2021; Yitmen and Alizadehsalehi, 2021a, b; Yitmen et al., 2021)

Internet of things (Gamil et al., 2020; Mahmud et al., 2018; Oke and Arowoiya, 2021; Woodhead et al., 2018)
Questionnaire statement

BIM Level 2 "BIM supported simulations and collaboration" is implemented as collaborative working and information exchange methods

Cloud-based common data environment is one of the main challenges for the full implementation of BIM Level 3 "BIM integrated with Io T"

BIM clash detection and resolution reduce rework and delayed schedules

4D BIM planning and scheduling are used for progress monitoring

Reality capture technologies are used for automated data collection from site From 3D point clouds to as-built models are used to revise design and update the progress of construction

Digital reality improves efficiencies by making smart and informed decisions DT helps to formulate a data-centric mode of smart planning and construction

DT facilitates generative design process by using AI

DT helps to optimize creativity in design process

DT helps support visualizations, simulations and scenario generations applications

DT leverages the data streaming from a variety of site monitoring technologies and artificially intelligent functions

DT provides accurate status information to proactively analyze and optimize ongoing design, planning and construction

A DT provides real-time and effective decisions based on well-informed and reliable what-if scenario assessments DT provides long-term feedback for design and planning

Io $\mathrm{T}$ is included in DT as connecting the physical and virtual worlds

IoT facilitate to integrate and share data by a network of interconnected physical devices

IoT promote the efficiency of the data collection, data transmission, data processing based on cloud computing IoT solution support real-time data transformation and instantaneous data analysis

IoT-based sensing systems help feasibly track the progress and monitor the worksite IoT help to automate the real-time decision making
Construction

$\begin{array}{lll}4.15 & 0.894 \quad 9\end{array}$

$3.88 \quad 1.060 \quad 14$

$\begin{array}{lll}4.25 & 0.947 \quad 5\end{array}$

$\begin{array}{lll}3.71 & 1.289 \quad 18\end{array}$

$3.71 \quad 1.073 \quad 18$

$3.88 \quad 1.215 \quad 14$

$\begin{array}{lll}4.37 & 0.841 & 3\end{array}$

$\begin{array}{lll}4.21 & 0.848 \quad 6\end{array}$

$3.79 \quad 1.073 \quad 16$

$3.85 \quad 1.073 \quad 15$

$\begin{array}{lll}4.42 & 0.801 & 1\end{array}$

$4.13 \quad 0.950 \quad 10$

$\begin{array}{lll}4.13 & 0.971 \quad 10\end{array}$

$\begin{array}{lll}4.27 & 0.910 \quad 4\end{array}$

$\begin{array}{lll}4.23 & 0.942 \quad 6\end{array}$

$\begin{array}{lll}4.17 & 1.004 & 8\end{array}$

$\begin{array}{lll}4.19 & 0.841 & 7\end{array}$

$\begin{array}{lll}4.38 & 0.771 & 2\end{array}$

$4.25 \quad 0.860 \quad 5$

$3.96 \quad 1.102 \quad 13$

$\begin{array}{lll}4.19 & 0.886 \quad 8\end{array}$

Table 7.

Descriptive statistics analysis 


\section{SASBE} 12,3

\section{4}

Factors/References
Deep learning (Akanbi et al., 2020; Darko
et al., 2020; Hou et al., 2021a; Zhang et al.,
2019)

Process Optimization (Akanbi et al., 2020; Matar et al., 2013; Oprach et al., 2019)
Table 7.

\begin{tabular}{|c|c|c|c|}
\hline Questionnaire statement & Mean & SD & Rank \\
\hline $\begin{array}{l}\text { Current challenges promote exploiting the } \\
\text { use of DL in tackling construction problems }\end{array}$ & 3.87 & 0.950 & 13 \\
\hline $\begin{array}{l}\text { DL facilitate the huge amount of recorded } \\
\text { data to analyzed and offer actinal insights } \\
\text { for better supervision and decision-making }\end{array}$ & 4.02 & 0.918 & 8 \\
\hline $\begin{array}{l}\text { DL is required to construct a self-reliant, } \\
\text { self-updatable and self-learning DT }\end{array}$ & 3.96 & 0.928 & 13 \\
\hline $\begin{array}{l}\text { DL enables autonomous DT that generates } \\
\text { predictive insights and foster continuous } \\
\text { optimization processes }\end{array}$ & 4.10 & 0.934 & 11 \\
\hline $\begin{array}{l}\text { DL facilitate to automate generative design } \\
\text { process }\end{array}$ & 3.79 & 0.997 & 16 \\
\hline $\begin{array}{l}\text { DL support to solve cash flow prediction, } \\
\text { onsite safety and project risk mitigated } \\
\text { analysis in construction }\end{array}$ & 4.06 & 0.873 & 10 \\
\hline $\begin{array}{l}\text { The simulation, prediction and optimization } \\
\text { abilities of a DT are inter-dependent and act } \\
\text { in unison in solving the problems in } \\
\text { planning, design and construction }\end{array}$ & 4.02 & 0.874 & 12 \\
\hline $\begin{array}{l}\text { DT facilitates dynamic optimization } \\
\text { technologies that enable real-time system } \\
\text { reflections and automatic model } \\
\text { evolvement with updated data feed }\end{array}$ & 4.13 & 0.841 & 10 \\
\hline $\begin{array}{l}\text { Optimization process depends on the } \\
\text { simulated prediction ("what will happen?") } \\
\text { applied for planning, or various other } \\
\text { construction management objectives }\end{array}$ & 4.25 & 0.813 & 5 \\
\hline $\begin{array}{l}\text { DT enables pro-active modeling, tracking } \\
\text { and optimization of construction processes } \\
\text { and their associated off- and on-site } \\
\text { resources }\end{array}$ & 4.02 & 0.939 & 12 \\
\hline $\begin{array}{l}\text { Optimization would be fully entrusted to the } \\
\text { DT's goals and learning patterns in agent- } \\
\text { driven socio/technical platforms }\end{array}$ & 3.73 & 0.931 & 17 \\
\hline $\mathrm{OM}$ & 4.064 & & \\
\hline
\end{tabular}

importance of the variables, the statement "IoT promote the efficiency of data collection, data transmission and data processing based on cloud computing" from IoT had the highest mean of $x=4.38$ in terms of relative importance. "DT facilitates generative design process by using AI" from DT had the second highest mean of $x=4.32$, behind only "DT facilitates generative design process by using AI." In the study, the statement "Digital reality improves efficiencies by allowing people to make smart and informed decisions" from DT received the thirdhighest mean of $x=4.37$. Regarding smart planning and construction, most respondents believed that the DL integrated DT model will encompass cognitive abilities to identify complicated and unpredictable activities, reasoning about dynamic process optimization techniques and decision-making.

\subsection{Correlation analysis}

Table 8 shows the results of a correlation analysis of respondents' perceptions of the decision support capabilities of DL integrated DTs based on their perceptions of DL integration. It is a statistical method that is used to determine whether or not there is a relationship between two variables or data sets, as well as how strong that relationship might be. 
The correlation matrix is examined, and it is discovered that the significant values of the correlation are greater than 0.5 , indicating that the matrix is suitable for factorization. As shown in Table 9, the Bartlett sphericity test is also significant, and the Kaiser-Meyer-Olkin sampling adequacy ratio is greater than 0.6, indicating that the sample is sufficiently representative. According to the calculations, the strongest correlation between DL and smart planning and construction was calculated to be $r=0.812$. In the second strongest correlation, calculated as $r=0.743$, the relationship between DL and DT was found to be the most significant. In the case of IoT and DT, the weakest correlation was calculated to be $r=0.558$. It is a statistical method that is used to determine whether or not there is a relationship between two variables or data sets, as well as how strong that relationship might be.

\subsection{Thematic analysis}

The thematic analysis stage of the research process is the final step in the process. Based on the responses from the interviews and group focus meetings, NVivo 12 was used to create thematic analysis in Table 10. NVivo is a qualitative and mixed-methods research software program that is used in many different types of research. In particular, it examines interviews, focus groups, surveys, social media and journal publications. It is a statistical method that is used to determine whether or not there is a relationship between two variables or data sets, as well as how strong that relationship might be.

\subsection{Model of framework}

In order to develop a management system for any practical purpose, it is necessary to first gain an understanding of the process details. A schematic representation of the integrated DL model at various stages of planning, design and construction is depicted schematically in Figure 3. The framework model is a step towards the next level of DT, which will involve process automation and control in the direction of Construction 4.0, which will be implemented for different phases of the project lifecycle (design-planning-construction). For smart planning and construction, IoT, ML and big data integration are all linked to

\begin{tabular}{|c|c|c|c|c|c|}
\hline Spearman's rank corr & $\begin{array}{l}\text { ion coefficient matrix } \\
\text { Smart planning and } \\
\text { construction }\end{array}$ & $\begin{array}{l}\text { Digital } \\
\text { twin }\end{array}$ & $\begin{array}{l}\text { Internet of } \\
\text { things }\end{array}$ & $\begin{array}{l}\text { Deep } \\
\text { learning }\end{array}$ & $\begin{array}{c}\text { Process } \\
\text { optimization }\end{array}$ \\
\hline $\begin{array}{l}\text { Smart Planning and } \\
\text { Construction }\end{array}$ & 1.000 & & & & \\
\hline Digital twin & $0.654^{*}$ & 1.000 & & & \\
\hline Internet of things & $0.617^{*}$ & $0.558^{*}$ & 1.000 & & \\
\hline Deep learning & $0.812^{*}$ & $0.743^{*}$ & $0.609^{*}$ & 1.000 & \\
\hline Process Optimization & $0.640^{*}$ & $0.661^{*}$ & $0.627^{*}$ & 0.664 & 1.000 \\
\hline
\end{tabular}

\section{Construction}

Table 8

Correlation analysis of respondents' perception on DL integrated DTs' decision support capabilities
Kaiser-Meyer-Olkin measure of sampling adequacy Bartlett's test of sphericity

$\begin{array}{lc} & 0.768 \\ \text { Approx. Chi-square } & 1136.094 \\ \text { df } & 496 \\ \text { Siq } & 0.000\end{array}$

Table 9.

Kaiser-Meyer-Olkin and Bartlett's test 


\section{SASBE 12,3}

476

Table 10.

Thematic analysis of the interviews and group focus meeting responses
Coded themes

Benefits of BIM Level 2 (BIM-supported simulations and collaboration) implementation

Challenges for the implementation of BIMLevel 3 (BIM integrated with IoT)

Integration of IoT and AI agents (data analytics, ML, DL) through semantic models

DT promises progressing towards Construction 4.0

Role of AI for prediction and optimization in DT realization

Challenges in construction process optimization abilities of DT

Achievable level of interoperability between DT and DL towards Construction 4.0

Added value of DT and DT for process optimization in construction
Thematic answer summary analysis

BIM-supported simulations help in project planning and on-site trade coordination for critical construction areas. It saves time and reduces cost. BIM collaboration helps in real-time clash checks and coordination with the stakeholders, saves onsite wastage and reduces coordination time. Digitization first as it assumes no paper model anymore. Collaboration is easier, but reconciling each party's model can certainly be a challenge

Gives the full perspective of the process and brings all the disciplines on the same round. It helps a lot in reducing the clashes that might happen during the construction process

Specifications or dimensions are set for each object and standards are set for the production, exchange and archiving of information in one package

Involves developing building information in a collaborative 3D environment with data attached, but created in separate discipline models

Improving processes and increasing the efficiency of the construction industry in an intelligent environment Integrating data in a smart environment

Implementing, improving processes and increasing the efficiency of the construction industry. Discipline in the building design environment

Managing the data with related parts and optimizing the conclusion
Figure 3.

DL integrated DT (DDT) model of framework

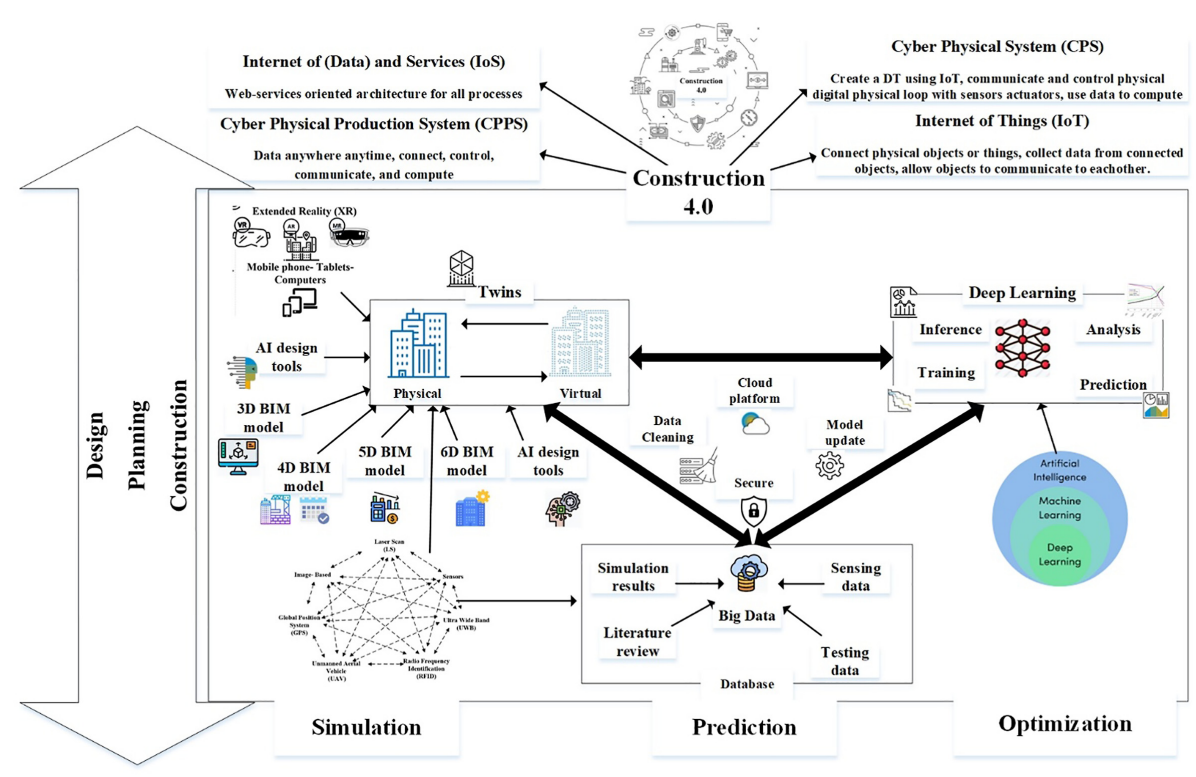


self-learning hybrid models with proactive cognitive capabilities. The DL integrated DT model will help decision-making better judgments in real-time through the interplay of optimization and simulation by incorporating cognitive ability to recognize complicated and unpredictable activities, as well as reasoning about dynamic process optimization techniques. It is a statistical method that is used to determine whether or not there is a relationship between two variables or data sets, as well as how strong that relationship might be. Project data to be used in design, planning and construction stages has increased almost exponentially since BIM adoption, experiencing what is termed "data-based drawings."

As shown in Figure 3, DDT in the proposed framework can now be applied throughout the full building lifecycle from design to construction and is effective in terms of 4D, 5D and 6D BIM models as traditionally utilized at the simple BIM models. Decision-making has been automated through the use of DL to reduce reliance on humans and to provide autonomous functionalities that are repeatable and consistent in their outcomes. With the use of DDT, it is hoped that transparency will be improved throughout the entire operating network. By integrating real-time and historical data from machines and inventory, as well as information from suppliers, customers and maintenance technicians into DT models, the proposed DDT model of framework helps simulate and optimize predictive maintenance strategies for the components. Various historical data as the main database with the help of various AI design tools will generate the best 3D BIM model scenarios accessible to use in XR devices.

DT enables building stakeholders to harness nD BIM data throughout the design process and ultimately improve operations in the construction stage. These processes help the visualization to be clear and specific to user's needs and to support collaborative and coordination meetings, from a functional as well as from an ergonomic perspective. DDT is dynamic, and it is more than just a collection of 3D models starting from the design phase of a project. DDT from the construction stage incorporates sensors, IoT technologies and AI, feeding real-time data back into the digital $\mathrm{nD}$-models. It evolves with input and gives stakeholders new insights. In this stage, when the optimized plan is ready, it is sent back to the physical system, along with supplementary visual information to be implemented. All models work independently and collaboratively to build a closed-loop predictive framework, which is achieved by iteratively repeating this process in a semi-real-time environment.

\section{Discussion and implications}

\subsection{Theoretical contributions}

When it comes to construction, the novelty of the next-generation design-thinking concept, which can be integrated with digital learning and leveraged in the same way that it has been in other industries, was the driving force behind this study. When compared to the applications of other digital technologies such as BIM and other ML algorithms, there are currently insufficient DL applications in the DT industry at this time (Akinosho et al., 2020; Braun and Borrmann, 2019). What constitutes a technically justifiable DT platform integrating DT and DL to facilitate smart planning and construction is the subject of this study. It also investigates how capacity can be developed in order to seize opportunities and overcome constraints associated with the implementation of DL integrated DT applications to simulate and optimize planning and construction processes are the subject of this study.

DL integrated DT model facilitating smart planning and construction will incorporate cognitive abilities to detect complex and unpredictable actions, as well as reasoning about dynamic process optimization strategies to support decision-making, as revealed by the quantitative and qualitative analyses of the data collected from the surveys, interviews and group focus meetings (Yitmen et al., 2021). When used in conjunction with other data sources, such as physical counterparts and sensors from all aspects of an industrial system's 
SASBE 12,3

operational conditions, the semantic-driven detection, learning, prediction, inference, estimation and decision capabilities of the DL integrated DT model will be enhanced. In addition to cognitive abilities such as anomaly detection and behavioral learning during the construction process, the DL integrated DT model will provide the capability to decide on the actions of the physical twin to improve the measures defining its state or function (Eirinakis et al., 2020).

DT makes use of real-time data streaming from a variety of site monitoring technologies, as well as artificially intelligent features. The IoTs improve the efficiency of data collection, data transmission and data processing through the use of cloud computing. DT is assisting in the formulation of a data-centric model for smart planning and construction (see Figure 1). By utilizing AI, DT makes the generative design process more efficient. The IoTs' solutions enable real-time data transformation and instantaneous data analytics. Construction processes and their associated off- and on-site resources can be modeled, tracked and optimized in real-time using digital technology. In agent-driven socio-technical platforms, optimization would be completely delegated to the DT's goals and learning patterns, with no human intervention (Turner et al., 2020).

Planning, designing and delivering built assets more effectively and efficiently are all made possible by Construction 4.0, with a particular emphasis on the physical-to-digital transition and subsequently the digital-to-physical transformation. DDT allows for tighter connections between computer models and physical entities, bridging the existing gap and therefore being termed the "heart" of Construction 4.0 (Akanmu et al., 2021; Begic and Galić, 2021).

The dependability and interoperability of BIM-based data transmission is critical in such applications. Further, machine-aided rule interpretation might lead to complicated disputes. The accuracy of BIM models impacts the performance of DDTs. When imported into reality simulation platforms, the models can be used to perform what-if scenarios and make decisions in real-time (Karmakar and Delhi, 2021).

Sensors and data communication technologies enable resource networks to connect and exchange data. Such data are vital for establishing relationships between processes, operations and resources, creating models that can predict physical system behavior and managing the physical world (Akanmu et al., 2021).

The IoT is a network of interconnected physical devices that makes integration and data sharing easier (Turner et al., 2020). Due to real-time data analytics, IoT in construction offers various possibilities and advantages. Moreover, IoT applications and technology can improve user comfort, security and energy efficiency throughout construction, maintenance and operation. Utilizing IoT, real-time data from a construction site drives BIM models to track progress. Current IoT solutions in construction are regarded to be isolated for specific applications but lack coordination throughout the entire construction process (Begic and Galić, 2021). The use of DT in the built environment may be considerably enhanced by providing real-time automated control with the potential to expand the number of scenarios examined in order to improve the efficiency and reliability of the control systems via DDT system.

The DT has limited intelligence, depending on inherent knowledge rules as well as independent AI-enabled simulations and forecasts to make decisions and make predictions. This generation needs a large amount of human intervention in order to carry out DT optimization and operation (Deng et al., 2021). One of the most important tasks that may be accomplished with a DT is connection and data fusion, which mostly relates to preparing large amounts of data, data mining and real-time optimization. Physical entities and several related applications may create data, which can make determining the appropriate data format and type, as well as ensuring reliable communication across all of the relevant devices and entities, challenging. Connectivity is a vital component of smart systems, such as smart 
construction, and it should be increased as a fundamental demand of DT to achieve greater efficiency (Sepasgozar, 2021).

The potential benefits of ML in construction are increasingly well known through predictive analytics applications and ML capabilities have continued to grow, especially in areas such as DL (Venkatasubramanian, 2021). The predictive model to predict failures is based on a DL model and can be reused on similar installations in different facilities by using transfer learning, which can allow one to cut the development cost and reduce the implementation time (Bouabdallaoui et al., 2021). There are DL approaches to create solutions to construction problems like generative design, cash flow prediction and project risk analysis. However, the availability of data, due to the widespread use of predictive analytics applications, the potential advantages of DL in construction are becoming more widely recognized, and the capability of DL has continued to develop, particularly in areas such as DT. By utilizing learning algorithm, the predictive model to forecast failures may be reused on identical installations in multiple facilities, providing for a reduction in development costs and a decrease in implementation time (Bouabdallaoui et al., 2021). For construction challenges such as generative design, cash flow prediction and project risk analysis, there are DL techniques that may be used to generate solutions. In the AEC industry, however, some of the current hurdles include data availability, data privacy and ethics, as well as a lack of inhouse capabilities for DL and adversarial ML.

\subsection{Practical implications}

The DDT system developed in this study automates and speeds up the time-consuming management task. To construct 3D models and produce XR models, DDT in the design stage helps AI technologies to extract knowledge and learn from obtained raw data. As part of the planning stage, DDT creates 4D models that optimize the construction process and resource allocation, properly estimating budgetary requirements and analyzing economic and operational elements throughout the lifecycle. Using CPSs and technology to understand and regulate progress, DDT automatically learns from collected data, and facilitates workflow optimization of the construction process to make better judgments. As the opportunities, DDT uses cognitive algorithms to improve design procedures, while XR's immersive nature helps visualize and evaluate designs. With real-time cost display and communication of changes in expenses, DDT ensures accurate energy consumption forecasting and early conflict detection in the planning stage. In the construction stage, it uses cognitive analytics to increase construction accuracy by combining reasoning and optimization.

However, the DDT model involves challenges of lacking historical data availability and validation, complicated environment modeling and skilled human resources. Also, experienced crew, adequate IT infrastructure in the planning stage, and lack of complete modeling language, scalability and large-scale computation in the construction stage are other challenges of the proposed model. Table 11 presents a sample of the DDT model processes, opportunities and challenges for design, planning and construction.

\subsection{Future work}

The purpose of this study was to investigate and debate the possibility and ways of combining ML with decision-making DT technology. At the present, the research and application of DT technology are still in the early stages of development and refinement, and a significant amount of time and effort is required. The findings of this research were limited in its insight due to the limited number of professionals from various industrial sectors who participated in it. An increased number of samples on a larger scale and response rate are recommended to improve the future study's reliability. Future research on this topic needs to be undertaken as follows: (1) to enhance the DT models at each stage and accumulate, 


\begin{tabular}{|c|c|c|c|c|}
\hline \multirow{2}{*}{$\begin{array}{l}\text { SASBE } \\
12,3\end{array}$} & \multicolumn{2}{|r|}{ Process } & Opportunities & Challenges \\
\hline & Design & $\begin{array}{l}\text { Facilitating AI tools to } \\
\text { extract knowledge and learn } \\
\text { from collected raw data, } \\
\text { applying generative design } \\
\text { to create 3D models and } \\
\text { develop XR models }\end{array}$ & $\begin{array}{l}\text { Implementing intelligent- } \\
\text { based algorithms to improve } \\
\text { design practices, and with } \\
\text { immersive nature of XR } \\
\text { visualizing and evaluating } \\
\text { designs more effectively }\end{array}$ & $\begin{array}{l}\text { Lack of historical data } \\
\text { availability and validation of } \\
\text { data, complex environment } \\
\text { modeling and competent } \\
\text { human resources }\end{array}$ \\
\hline & Planning & $\begin{array}{l}\text { Developing } 4 \text { D models with } \\
\text { scheduling optimization } \\
\text { construction process and } \\
\text { resource allocation, } \\
\text { accurately predicting the } \\
\text { budgetary requirements } \\
\text { along with the changes in } \\
\text { scope, material, manpower } \\
\text { or equipment requirements, } \\
\text { and analyzing economic and } \\
\text { operational aspects over the } \\
\text { entire lifecycle }\end{array}$ & $\begin{array}{l}\text { Helping in early conflict } \\
\text { detection by seamlessly } \\
\text { managing information } \\
\text { related to site status and } \\
\text { visualizing the impact of } \\
\text { changes undertaken during } \\
\text { the entire lifecycle, real-time } \\
\text { cost visualization with } \\
\text { notification on changes in } \\
\text { costs, and ensuring accurate } \\
\text { prediction of energy } \\
\text { consumption requirements }\end{array}$ & $\begin{array}{l}\text { Lack of fully automated } \\
\text { digital platform, experienced } \\
\text { staff, and IT infrastructure }\end{array}$ \\
\hline $\begin{array}{l}\text { Table } 11 \text {. } \\
\text { Sample of DDT model } \\
\text { processes, } \\
\text { opportunities and } \\
\text { challenges for design, } \\
\text { planning and } \\
\text { construction }\end{array}$ & Construction & $\begin{array}{l}\text { Sensing and capturing real- } \\
\text { time data using CPSs and } \\
\text { technologies (drone, WSN, } \\
\text { AR etc.) to comprehend and } \\
\text { control the progress, } \\
\text { automatically learning from } \\
\text { collected data and workflow } \\
\text { optimization of the } \\
\text { construction process to } \\
\text { make better decisions }\end{array}$ & $\begin{array}{l}\text { Applying cognitive analytics } \\
\text { through data-enriched } \\
\text { simulations and combining } \\
\text { reasoning and optimization } \\
\text { for improved accuracy of } \\
\text { construction schemes }\end{array}$ & $\begin{array}{l}\text { IoT network in terms of } \\
\text { scalability, integration of } \\
\text { transfer learning algorithms, } \\
\text { lack of comprehensive } \\
\text { modeling language and large- } \\
\text { scale computation }\end{array}$ \\
\hline
\end{tabular}

integrate and apply life cycle information; (2) to develop a synchronous and efficient mapping mechanism between physical and virtual data to fulfill the needs of real-time analysis and dynamic decision-making; (3) to build the system structure and workflow of a DL, IoT and integrated DT model that can assist in automating real-time decision making at an operational level to remotely manage the construction worksite, optimize project performance and anticipate future circumstances.

\section{Conclusions}

It was discovered that DDTs play an important role in the AEC industry, and it was presented as a model of a framework called DDT framework. There are a number of processes that describe how these technologies collaborate to manage data and information in AEC projects, which are listed above. The findings demonstrate unequivocally that there is widespread awareness of the real-world implications of DT integration with DL and IoT in order to efficiently resolve previously unknown situations. When this model of the framework is implemented, it will allow for better real-time decision-making through the interaction of optimization and simulation during the planning and construction phases of the project.

Despite the fact that this study identifies a number of promising research areas for the future, it also contains some significant limitations. The findings of this study were limited in their insight due to the small number of specialists from various industry sectors who participated in it. It is recommended that the number of samples be increased on a larger scale, as well as the response rate, in order to improve the reliability of future studies. 


\section{References}

Abdelkader, E.M. (2021), "On the hybridization of pre-trained deep learning and differential evolution algorithms for semantic crack detection and recognition in ensemble of infrastructures", Smart and Sustainable Built Environment, Vol. ahead-of-print No. ahead-of-print, doi: 10.1108/SASBE01-2021-0010.

Aheleroff, S., Xu, X., Zhong, R.Y. and Lu, Y. (2021), "Digital twin as a service (DTaaS) in industry 4.0: an architecture reference model", Advanced Engineering Informatics, Vol. 47, p. 101225, doi: 10. 1016/j.aei.2020.101225.

Akanbi, L.A., Oyedele, A.O., Oyedele, L.O. and Salami, R.O. (2020), "Deep learning model for Demolition Waste Prediction in a circular economy", Journal of Cleaner Production, Vol. 274, p. 122843, doi: 10.1016/j.jclepro.2020.122843.

Akanmu, A.A., Anumba, C.J. and Ogunseiju, O.O. (2021), "Towards next generation cyber-physical systems and digital twins for construction", Journal of Information Technology in Construction (ITcon), Vol. 26 No. 27, pp. 505-525, doi: 10.36680/j.itcon.2021.027.

Akinosho, T.D., Oyedele, L.O., Bilal, M., Ajayi, A.O., Delgado, M.D., Akinade, O.O. and Ahmed, A.A. (2020), "Deep learning in the construction industry: a review of present status and future innovations", Journal of Building Engineering, Vol. 32, p. 101827, doi: 10.1016/j.jobe. 2020.101827.

Alavi, A.H., Jiao, P., Buttlar, W.G. and Lajnef, N. (2018), "Internet of Things-enabled smart cities: stateof-the-art and future trends”, Measurement, Vol. 129, pp. 589-606, doi: 10.1016/j.measurement. 2018.07.067.

Alizadehsalehi, S. and Yitmen, I. (2021), "Digital twin-based progress monitoring management model through reality capture to extended reality technologies (DRX)", Smart and Sustainable Built Environment, Vol. ahead-of-print No. ahead-of-print, doi: 10.1108/SASBE-01-2021-0016.

Alawadhi, M. and Yan, W. (2021), BIM Hyperreality: Data Synthesis Using BIM and Hyperrealistic Rendering for Deep Learning, arXiv preprint arXiv:2105.04103.

Alizadehsalehi, S., Hadavi, A. and Huang, J.C. (2020), "From BIM to extended reality in AEC industry", Automation in Construction, Vol. 116, p. 103254, doi: 10.1016/j.autcon.2020.103254.

Alonso, R., Borras, M., Koppelaar, R.H., Lodigiani, A., Loscos, E. and Yöntem, E. (2019), "SPHERE: BIM digital twin platform", Multidisciplinary Digital Publishing Institute Proceedings. doi: 10. 3390/proceedings2019020009.

Alshammari, K., Beach, T.H. and Rezgui, Y. (2021), "Cybersecurity for digital twins in the built environment: current research and future directions", Journal of Information Technology in Construction, Vol. 26, pp. 159-173, doi: 10.36680/j.itcon.2021.010.

Arthur, S., Li, H. and Lark, R. (2018), "The emulation and simulation of internet of things devices for building information modelling (BIM)", Workshop of the European Group for Intelligent Computing in Engineering, Springer, Cham, doi: 10.1007/978-3-319-91638-5_18.

Atazadeh, B., Olfat, H., Rismanchi, B., Shojaei, D. and Rajabifard, A. (2019), "Utilizing a building information modelling environment to communicate the legal ownership of internet of thingsgenerated data in multi-owned buildings", Electronics, Vol. 8 No. 11, p. 1258, doi: 10.3390/ electronics8111258.

Bakhshi, S., Chenaghlou, M.R., Rahimian, F.P., Edwards, D.J. and Dawood, N. (2022), "Integrated BIM and DfMA parametric and algorithmic design based collaboration for supporting client engagement within offsite construction", Automation in Construction, Vol. 133, p. 104015, doi: 10.1016/j.autcon.2021.104015.

Begić, H. and Galić, M. (2021), "A systematic review of construction 4.0 in the context of the BIM 4.0 premise”, Buildings, Vol. 11 No. 8, p. 337, doi: 10.3390/buildings11080337.

Boje, C., Guerriero, A., Kubicki, S. and Rezgui, Y. (2020), "Towards a semantic construction digital twin: directions for future research", Automation in Construction, Vol. 114, p. 103179, doi: 10. 1016/j.autcon.2020.103179.

\section{Construction}


SASBE 12,3
Bosch-Sijtsema, P., Claeson-Jonsson, C., Johansson, M. and Roupe, M. (2021), "The hype factor of digital technologies in AEC", Construction Innovation, Vol. 21 No. 4, pp. 899-916, doi: 10.1108/CI01-2020-0002.

Bouabdallaoui, Y., Lafhaj, Z., Yim, P., Ducoulombier, L. and Bennadji, B. (2021), "Predictive maintenance in building facilities: a machine learning-based approach”, Sensors, Vol. 21 No. 4, p. 1044, doi: 10.3390/s21041044.

Braun, A. and Borrmann, A. (2019), "Combining inverse photogrammetry and BIM for automated labeling of construction site images for machine learning”, Automation in Construction, Vol. 106, p. 102879, doi: 10.1016/j.autcon.2019.102879.

Camposano, J.C., Smolander, K. and Ruippo, T. (2021), "Seven metaphors to understand digital twins of built assets”, IEEE Access, Vol. 9, pp. 27167-27181, doi: 10.1109/ACCESS.2021.3058009.

Cardno, C.A. (2020), “Companies offer free tech during COVID-19 slowdown”, Civil Engineering Magazine Archive, Vol. 90 No. 5, pp. 40-43, doi: 10.1061/ciegag.0001500.

Chang, C.-H., Lin, C.-Y., Wang, R.-G. and Chou, C.-C. (2019), "Applying deep learning and building information modeling to indoor positioning based on sound", in Computing in Civil Engineering 2019: Visualization, Information Modeling, and Simulation, American Society of Civil Engineers, Reston, VA, pp. 193-199, doi: 10.1061/9780784482421.025.

Chen, S. and Demachi, K. (2021), "Towards on-site hazards identification of improper use of personal protective equipment using deep learning-based geometric relationships and hierarchical scene graph”, Automation in Construction, Vol. 125, p. 103619, doi: 10.1016/j.autcon.2021.103619.

Craveiroa, F., Duartec, J.P., Bartoloa, H. and Bartolod, P.J. (2019), "Additive manufacturing as an enabling technology for digital construction: a perspective on Construction 4.0”, Sustainable Development, Vol. 4, p. 6, doi: 10.1016/j.autcon.2019.03.011.

Cureton, P. and Dunn, N. (2021), "Digital twins of cities and evasive futures", Shaping Smart for Better Cities, Elsevier, London, pp. 267-282.

Darko, A., Chan, A.P., Adabre, M.A., Edwards, D.J., Hosseini, M.R. and Ameyaw, E.E. (2020), "Artificial intelligence in the AEC industry: scientometric analysis and visualization of research activities”, Automation in Construction, Vol. 112, p. 103081, doi: 10.1016/j.autcon.2020.103081.

Dawood, N., Pour Rahimian, F., Seyedzadeh, S. and Sheikhkhoshkar, M. (2020), Enabling the Development and Implementation of Digital Twins: Proceedings of the 20th International Conference on Construction Applications of Virtual Reality, Tesside University Press, Middlesbrough, ISBN: 9780992716127.

Del Giudice and Osello, A. (2021), Handbook of Research on Developing Smart Cities Based on Digital Twins, IGI Global, Hershey, ISBN: 9781799870937.

Deng, M., Menassa, C.C. and Kamat, V.R. (2021), "From BIM to digital twins: a systematic review of the evolution of intelligent building representations in the AEC-FM industry", Journal of Information Technology in Construction (ITcon), Vol. 26 No. 5, pp. 58-83, doi: 10.36680/j.itcon. 2021.005.

Ding, K., Shi, H., Hui, J., Liu, Y., Zhu, B., Zhang, F. and Cao, W. (2018), "Smart steel bridge construction enabled by BIM and Internet of Things in industry 4.0: a framework", 2018 IEEE 15th International Conference on Networking, Sensing and Control (ICNSC), IEEE, Zhuhai, doi: 10. 1109/ICNSC.2018.8361339.

Eirinakis, P., Kalaboukas, K., Lounis, S., Mourtos, I., Rožanec, J.M., Stojanovic, N. and Zois, G. (2020), "Enhancing cognition for digital twins", 2020 IEEE International Conference on Engineering, Technology and Innovation (ICE/ITMC), IEEE, Cardiff, doi: 10.1109/ICE/ITMC49519.2020. 9198492.

Feng, D. and Chen, H. (2021), "A small samples training framework for deep learning-based automatic information extraction: case study of construction accident news reports analysis", Advanced Engineering Informatics, Vol. 47, p. 101256, doi: 10.1016/j.aei.2021.101256. 
Galanos, T. and Chronis, A. (2021), "A deep-learning approach to real-time solar radiation prediction", in The Routledge Companion to Artificial Intelligence in Architecture, Routledge, Oxford, pp. 224-231, ISBN: 9780367824259.

Gamil, Y., Abdullah, M.A., Abd Rahman, I. and Asad, M.M. (2020), "Internet of things in construction industry revolution 4.0", Journal of Engineering, Design and Technology, Vol. 18 No. 5, pp. 10911102, doi: 10.1108/JEDT-06-2019-0164.

Ghosh, A., Edwards, D.J. and Hosseini, M.R. (2020), "Patterns and trends in Internet of Things (IoT) research: future applications in the construction industry", Engineering, Construction and Architectural Management, Vol. 28 No. 2, pp. 457-481, doi: 10.1108/ECAM-04-2020-0271.

Götz, C.S., Karlsson, P. and Yitmen, I. (2020), "Exploring applicability, interoperability and integrability of Blockchain-based digital twins for asset life cycle management", Smart and Sustainable Built Environment, Vol. ahead-of-print No. ahead-of-print, doi: 10.1108/SASBE-082020-0115.

Hasan, S.M., Lee, K., Moon, D., Kwon, S., Jinwoo, S. and Lee, S. (2021), “Augmented reality and digital twin system for interaction with construction machinery", Journal of Asian Architecture and Building Engineering, Vol. ahead-of-print No. ahead-of-print, doi: 10.1080/13467581.2020.1869557.

Hong, M., Peng, C., Niu, M. and Xu, Z. (2021), "Research on the construction effect evaluation system of smart CBD: a case study in Jiangbei new District, Nanjing, China", Advances in Civil Engineering, 2021, doi: 10.1155/2021/6683491.

Hou, L., Chen, H., Zhang, G.K. and Wang, X. (2021a), "Deep learning-based applications for safety management in the AEC industry: a review", Applied Sciences, Vol. 11 No. 2, p. 821, doi: 10.3390/ app11020821.

Hou, L., Wu, S., Zhang, G.K., Tan, Y. and Wang, X. (2021b), "Literature review of digital twins applications in construction workforce safety”, Applied Sciences, Vol. 11 No. 1, p. 339, doi: 10. 3390/app11010339.

Kaewunruen, S. and Lian, Q. (2019), "Digital twin aided sustainability-based lifecycle management for railway turnout systems", Journal of Cleaner Production, Vol. 228, pp. 1537-1551, doi: 10.1016/j. jclepro.2019.04.156.

Karmakar, A. and Delhi, V.S.K. (2021), "Construction 4.0: what we know and where we are headed", Journal of Information Technology in Construction (ITcon), Vol. 26 No. 28, pp. 526-545, doi: 10. 36680/j.itcon.2021.028.

Khajavi, S.H., Motlagh, N.H., Jaribion, A., Werner, L.C. and Holmström, J. (2019), "Digital twin: vision, benefits, boundaries, and creation for buildings", IEEE Access, Vol. 7, pp. 147406-147419, doi: 10.1109/ACCESS.2019.2946515.

Kim, J. and Lee, J.-K. (2020), "Stochastic detection of interior design styles using a deep-learning model for reference images", Applied Sciences, Vol. 10 No. 20, p. 7299, doi: 10.3390/app10207299.

Kumar, K. (2018), "The 4th industrial revolution", CIGFARO Journal (Chartered Institute of Government Finance Audit and Risk Officers), Vol. 18 No. 3, pp. 16-21, available at: https:urn: nbn:se:hj:diva-53385.

Kung, R.-Y., Pan, N.-H., Wang, C.C. and Lee, P.-C. (2021), “Application of deep learning and unmanned aerial vehicle on building maintenance”, Advances in Civil Engineering, 2021, doi: 10.1155/2021/ 5598690 .

Lee, J., Azamfar, M., Singh, J. and Siahpour, S. (2020), "Integration of digital twin and deep learning in cyber-physical systems: towards smart manufacturing", IET Collaborative Intelligent Manufacturing, Vol. 2 No. 1, pp. 34-36, doi: 10.1049/iet-cim.2020.0009.

Li, C., Dai, Z., Liu, X. and Sun, W. (2020), "Evaluation system: evaluation of smart city shareable framework and its applications in China”, Sustainability, Vol. 12 No. 7, p. 2957, doi: 10.3390/ su12072957.

Lin, Y.-C. and Cheung, W.-F. (2020), "Internet of Things (IoT) and internet enabled physical devices for Construction 4.0", in Construction 4.0, Routledge, London, pp. 350-369, ISBN: 9780429398100. 
SASBE 12,3

Linares, D.A., Anumba, C. and Roofigari-Esfahan, N. (2019), "Overview of supporting technologies for cyber-physical systems implementation in the aec industry", in Computing in Civil Engineering 2019: Data, Sensing, and Analytics, American Society of Civil Engineers, Reston, VA, pp. 495-504, doi: 10.1061/9780784482438.063.

Liu, Z., Zhang, A. and Wang, W. (2020), "A framework for an indoor safety management system based on digital twin”, Sensors, Vol. 20 No. 20, p. 5771, doi: 10.3390/s20205771.

Liu, C., Sepasgozar, S.M., Shirowzhan, S. and Mohammadi, G. (2021), "Applications of object detection in modular construction based on a comparative evaluation of deep learning algorithms", Construction Innovation, Vol. 22 No. 1, pp. 141-159, doi: 10.1061/9780784482438.063.

Lokshina, I.V., Greguš, M. and Thomas, W.L. (2019), "Application of integrated building information modeling, IoT and blockchain technologies in system design of a smart building", Procedia Computer Science, Vol. 160, pp. 497-502, doi: 10.1016/j.procs.2019.11.058.

Lu, Q., Xie, X., Heaton, J., Parlikad, A.K. and Schooling, J. (2019), "From BIM towards digital twin: strategy and future development for smart asset management", International Workshop on Service Orientation in Holonic and Multi-Agent Manufacturing, Springer, Cham.

Ma, J.W., Czerniawski, T. and Leite, F. (2020), "Semantic segmentation of point clouds of building interiors with deep learning: augmenting training datasets with synthetic BIM-based point clouds", Automation in Construction, Vol. 113, p. 103144, doi: 10.1016/j.autcon.2020.103144.

Mahmud, S.H., Assan, L. and Islam, R. (2018), "Potentials of internet of things (IoT) in Malaysian construction industry", Annals of Emerging Technologies in Computing (AETiC), ISSN: 2516-0281.

Malagnino, A., Montanaro, T., Lazoi, M., Sergi, I., Corallo, A. and Patrono, L. (2021), "Building information modeling and Internet of Things integration for smart and sustainable environments: a review", Journal of Cleaner Production, Vol. 312, p. 127716, doi: 10.1016/j. jclepro.2021.127716.

Marzouk, M. and Zaher, M. (2020), "Artificial intelligence exploitation in facility management using deep learning”, Construction Innovation, Vol. 20 No. 4, pp. 609-624, doi: 10.1108/CI-12-2019-0138.

Matar, M., Osman, H., Georgy, M. and Abou-Zeid, A. (2013), "Sustainable construction modelling: a systems engineering approach", Smart and Sustainable Built Environments, Vol. 383, available at: https://www.irbnet.de/daten/iconda/CIB_DC27459.pdf.

Mathot, M., Hohrath, B., Rolvink, A. and Coenders, J. (2019), "Design modelling with next generation parametric system packhunt. io", Design Modelling Symposium Berlin, Springer, Cham.

Menassa, C.C. (2021), "From BIM to digital twins: a systematic review of the evolution of intelligent building representations in the AEC-FM Industry", Journal of Information Technology in Construction (ITcon), Vol. 26 No. 5, pp. 58-83, doi: 10.36680/j.itcon.2021.005.

Meža, S., Mauko Pranjić, A., Vezočnik, R., Osmokrović, I. and Lenart, S. (2021), "Digital twins and road construction using secondary raw materials", Journal of Advanced Transportation, Vol. 2021, doi: 10.1155/2021/8833058.

Ogunseiju, O.R., Olayiwola, J., Akanmu, A.A. and Nnaji, C. (2021), "Recognition of workers' actions from time-series signal images using deep convolutional neural network", Smart and Sustainable Built Environment, Vol. ahead-of-print No. ahead-of-print, doi: 10.1108/SASBE-112020-0170.

Oke, A.E. and Arowoiya, V.A. (2021), "Evaluation of internet of things (IoT) application areas for sustainable construction", Smart and Sustainable Built Environment, Vol. 10 No. 3, pp. 387-402, doi: 10.1108/SASBE-11-2020-0167.

Oprach, S., Bolduan, T., Steuer, D., Vössing, M. and Haghsheno, S. (2019), "Building the future of the construction industry through artificial intelligence and platform thinking", Digitale Welt, Vol. 3 No. 4, pp. 40-44, doi: 10.1007/s42354-019-0211-x.

Ozturk, G.B. (2021), "Digital twin research in the AECO-FM industry", Journal of Building Engineering, Vol. 40, p. 102730, doi: 10.1016/j.jobe.2021.102730. 
Pan, Y. and Zhang, L. (2021a), “A BIM-data mining integrated digital twin framework for advanced project management”, Automation in Construction, Vol. 124, p. 103564, doi: 10.1016/j.autcon. 2021.103564.

Pan, Y. and Zhang, L. (2021b), "Roles of artificial intelligence in construction engineering and management: a critical review and future trends", Automation in Construction, Vol. 122, p. 103517, doi: 10.1016/j.autcon.2020.103517.

Pasini, D., Ventura, S.M., Rinaldi, S., Bellagente, P., Flammini, A. and Ciribini, A.L.C. (2016), "Exploiting Internet of Things and building information modeling framework for management of cognitive buildings", 2016 IEEE International Smart Cities Conference (ISC2), IEEE, Trento, doi: 10.1109/ISC2.2016.7580817.

Perez-Perez, Y., Golparvar-Fard, M. and El-Rayes, K. (2021), "Scan2BIM-NET: deep learning method for segmentation of point clouds for scan-to-BIM", Journal of Construction Engineering and Management, Vol. 147 No. 9, 04021107, doi: 10.1061/(ASCE)CO.1943-7862.0002132.

Qi, Q., Tao, F., Zuo, Y. and Zhao, D. (2018), "Digital twin service towards smart manufacturing”, Procedia Cirp, Vol. 72, pp. 237-242, doi: 10.1016/j.procir.2018.03.103.

Quaye, G.M. (2021), "Digital twin implementation in operations and maintenance phase-components and Benefits", Master's Thesis, Aalborg University.

Rahimian, F.P., Seyedzadeh, S. and Glesk, I. (2019), "OCDMA-based sensor network for monitoring construction sites affected by vibrations", Journal of Information Technology in Construction, Vol. 24, pp. 299-317, ISSN: 1400-6529.

Rahimian, F.P., Goulding, J.S., Abrishami, S., Seyedzadeh, S. and Elghaish, F. (2021), Industry 4.0 Solutions for Building Design and Construction: A Paradigm of New Opportunities. doi: 10.1201/ 9781003106944-1.

Rausch, C., Sanchez, B., Esfahani, M.E. and Haas, C. (2020), "Computational algorithms for digital twin support in construction", in Construction Research Congress 2020: Computer Applications, American Society of Civil Engineers Reston, Reston, VA, doi: 10.1061/ 9780784482865.021.

Sacks, R., Brilakis, I., Pikas, E., Xie, H.S. and Girolami, M. (2020), "Construction with digital twin information systems", Data-Centric Engineering, Vol. 1, doi: 10.1017/dce.2020.16.

Sarkar, D., Patel, H. and Dave, B. (2020), "Development of integrated cloud-based Internet of Things (IoT) platform for asset management of elevated metro rail projects", International Journal of Construction Management, Vol. ahead-of-print No. ahead-of-print, doi: 10.1080/15623599.2020. 1762035.

Sawhney, A., Riley, M. and Irizarry, J. (2020), Construction 4.0: An Innovation Platform for the Built Environment, Routledge, Taylor \& Francis Group, London.

Sepasgozar, S.M. (2021), "Differentiating digital twin from digital shadow: elucidating a paradigm shift to expedite a smart, sustainable built environment”, Buildings, Vol. 11 No. 4, p. 151, doi: 10. 3390/buildings11040151.

Siountri, K., Skondras, E. and Vergados, D.D. (2020), "Developing smart buildings using blockchain, internet of things, and building information modeling", International Journal of Interdisciplinary Telecommunications and Networking (IJITN), Vol. 12 No. 3, pp. 1-15, doi: 10.4018/IJITN. 2020070101.

Tang, S., Shelden, D.R., Eastman, C.M., Pishdad-Bozorgi, P. and Gao, X. (2019), “A review of building information modeling (BIM) and the internet of things (IoT) devices integration: present status and future trends", Automation in Construction, Vol. 101, pp. 127-139, doi: 10.1016/j.autcon. 2019.01.020.

Tao, F., Qi, Q., Wang, L. and Nee, A. (2019), "Digital twins and cyber-physical systems toward smart manufacturing and industry 4.0: correlation and comparison”, Engineering, Vol. 5 No. 4, pp. 653-661, doi: 10.1016/j.eng.2019.01.014. 
SASBE 12,3

Turner, C.J., Oyekan, J., Stergioulas, L. and Griffin, D. (2020), "Utilizing industry 4.0 on the construction site: challenges and opportunities", IEEE Transactions on Industrial Informatics, Vol. 17 No. 2, pp. 746-756, doi: 10.1109/TII.2020.3002197.

ur Rehman, M.H., Yaqoob, I., Salah, K., Imran, M., Jayaraman, P.P. and Perera, C. (2019), "The role of big data analytics in industrial Internet of Things", Future Generation Computer Systems, Vol. 99, pp. 247-259, doi: 10.1016/j.future.2019.04.020.

Venkatasubramanian, K. (2021), "Machine learning set to play a key role in the transition to Construction 4.0", Proceedings of the Institution of Civil Engineers-Civil Engineering, Vol. 172 No. 2, p. 54, doi: 10.1680/jcien.2021.174.2.54.

Villa, V. and Chiaia, B. (2021), "Digital twin for smart school buildings: state of the art, challenges, and opportunities", Handbook of Research on Developing Smart Cities Based on Digital Twins, pp. 320-340, doi: 10.4018/978-1-7998-7091-3.ch015.

Wang, J., Chen, M., Zhou, J. and Li, P. (2020), "Data communication mechanism for greenhouse environment monitoring and control: an agent-based IoT system", Information Processing in Agriculture, Vol. 7 No. 3, pp. 444-455, doi: 10.1016/j.inpa.2019.11.002.

Wang, W., Gao, S., Mi, L., Xing, J., Shang, K., Qiao, Y., Fu, Y., Ni, G. and Xu, N. (2021), Exploring the Adoption of BIM amidst the COVID-19 Crisis in China, Building Research and Information, pp. 1-18.

Woodhead, R., Stephenson, P. and Morrey, D. (2018), "Digital construction: from point solutions to IoT ecosystem”, Automation in Construction, Vol. 93, pp. 35-46, doi: 10.1080/09613218.2021.1921565.

$\mathrm{Wu}, \mathrm{Z}$. (2018), "Intelligent city evaluation indicator systems in China", Intelligent City Evaluation System, Springer, Singapore, pp. 67-85.

Wu, J., Cai, N., Chen, W., Wang, H. and Wang, G. (2019), "Automatic detection of hardhats worn by construction personnel: a deep learning approach and benchmark dataset", Automation in Construction, Vol. 106, p. 102894, doi: 10.1016/j.autcon.2019.102894.

Wu, H., Shen, G., Lin, X., Li, M., Zhang, B. and Li, C.Z. (2020), "Screening patents of ICT in construction using deep learning and NLP techniques", Engineering, Construction and Architectural Management, Vol. 27 No. 8, pp. 1891-1912, doi: 10.1108/ECAM-09-2019-0480.

Xiao, B. and Kang, S.-C. (2021), "Vision-based method integrating deep learning detection for tracking multiple construction machines", Journal of Computing in Civil Engineering, Vol. 35 No. 2, 04020071, doi: 10.1061/(ASCE)CP.1943-5487.0000957.

Xu, Y., Zhou, Y., Sekula, P. and Ding, L. (2021), "Machine learning in construction: from shallow to deep learning", Developments in the Built Environment, Vol. 6, doi: 10.1016/j.dibe.2021.100045.

Xue, X. and Zhang, J. (2021), "Part-of-speech tagging of building codes empowered by deep learning and transformational rules", Advanced Engineering Informatics, Vol. 47, p. 101235, doi: 10.1016/ j.aei.2020.101235.

Yitmen, I. and Alizadehsalehi, S. (2021a), "Overview of cyber-physical systems and enabling technologies in cognitive computing for smart built environment", in BIM-enabled Cognitive Computing for Smart Built Environment, CRC Press, Boca Raton, pp. 1-20, ISBN: 9781003017547.

Yitmen, I. and Alizadehsalehi, S. (2021b), "Towards a digital twin-based smart built environment”, in BIM-enabled Cognitive Computing for Smart Built Environment, CRC Press, Boca Raton, pp. 21-44, ISBN: 9781003017547.

Yitmen, I., Alizadehsalehi, S., Akıner, İ. and Akıner, M.E. (2021), "An adapted model of cognitive digital twins for building lifecycle management", Applied Sciences, Vol. 11 No. 9, p. 4276, ISBN: 9781003017547.

Zhang, S., Yao, L., Sun, A. and Tay, Y. (2019), "Deep learning based recommender system: a survey and new perspectives", ACM Computing Surveys (CSUR), Vol. 52 No. 1, pp. 1-38, doi: 10.1145/ 3285029 . 
Zhong, R.Y., Peng, Y., Xue, F., Fang, J., Zou, W., Luo, H., Ng, S.T., Lu, W., Shen, G.Q. and Huang, G.Q. (2017), "Prefabricated construction enabled by the Internet-of-Things", Automation in Construction, Vol. 76, pp. 59-70, doi: 10.1016/j.autcon.2017.01.006.

Zhong, B., He, W., Huang, Z., Love, P.E., Tang, J. and Luo, H. (2020a), "A building regulation question answering system: a deep learning methodology", Advanced Engineering Informatics, Vol. 46, p. 101195, doi: 10.1016/j.aei.2020.101195.

Zhong, B., Pan, X., Love, P.E., Sun, J. and Tao, C. (2020b), "Hazard analysis: a deep learning and text mining framework for accident prevention", Advanced Engineering Informatics, Vol. 46, p. 101152, doi: 10.1016/j.aei.2020.101152.

\section{Corresponding author}

Ibrahim Yitmen can be contacted at: ibrahim.yitmen@ju.se

For instructions on how to order reprints of this article, please visit our website: 